\title{
BMJ Open A Service evaluation of a hospital child death review process to elucidate understanding of contributory factors to child mortality and inform practice in the English National Health Service
}

\author{
Daniel S Magnus, ${ }^{1}$ Margrid B Schindler, ${ }^{2}$ Robin D Marlow, ${ }^{3}$ James I Fraser ${ }^{4}$
}

To cite: Magnus DS,

Schindler MB, Marlow RD, et al. A Service evaluation of a hospital child death review process to elucidate understanding of contributory factors to child mortality and inform practice in the English National Health Service. BMJ Open 2018;8:e015802. doi:10.1136/ bmjopen-2016-015802

- Prepublication history and additional material for this paper are available online. To view these files, please visit the journal online (http://dx.doi. org/10.1136/bmjopen-2016015802).

Received 3 January 2017 Revised 28 November 2017 Accepted 26 January 2018

Check for updates

${ }^{1}$ Department of Emergency Medicine, Bristol Royal Hospital for Children, Bristol, UK

${ }^{2}$ Paediatric Intensive Care Unit, Bristol Royal Hospital for Children, Bristol, UK

${ }^{3}$ Population Health Sciences Department, Bristol Children's Hospital, Bristol, UK

${ }^{4}$ Paediatric Intensive Care Unit, Bristol Royal Hospital for Children, Bristol, UK

Correspondence to

Dr James I Fraser;

james.fraser@uhbristol.nhs.uk

\section{ABSTRACT}

Objective To describe a novel approach to hospital mortality meetings to elucidate understanding of contributory factors to child death and inform practice in the National Health Service.

Design All child deaths were separately reviewed at a meeting attended by professionals across the healthcare pathway, and an assessment was made of contributory factors to death across domains intrinsic to the child, family and environment, parenting capacity and service delivery. Data were analysed from a centrally held database of records.

Setting All child deaths in a tertiary children's hospital between 1 April 2010 and 1 April 2013.

Main outcome measures Descriptive data summarising contributory factors to child deaths.

Results 95 deaths were reviewed. In $85 \%$ cases, factors intrinsic to the child provided complete explanation for death. In $11 \%$ cases, factors in the family and environment and, in 5\% cases, factors in parenting capacity, contributed to patient vulnerability. In $33 \%$ cases, factors in service provision contributed to patient vulnerability and in two patients provided complete explanation for death. $26 \%$ deaths were classified as potentially preventable and in those cases factors in service provision were more commonly identified than factors across other domains (OR: $4.89 ; 95 \% \mathrm{Cl} 1.26$ to 18.9).

Conclusions Hospital child death review meetings attended by professionals involved in patient management across the healthcare pathway inform understanding of events leading to a child's death. Using a bioecological approach to scrutinise contributory factors the multidisciplinary team concluded most deaths occurred as a consequence of underlying illness. Although factors relating to service provision were commonly identified, they rarely provided a complete explanation for death. Efforts to reduce child mortality should be driven by an understanding of modifiable risk factors. Systematic data collection arising from a standardised approach to hospital reviews should be the basis for national mortality review processes and database development.
Strengths and limitations of this study

- It is possible to adopt a standardised approach, which involves multidisciplinary team (MDT) attendance across the healthcare pathway and a standardised framework to assess contributory and modifiable risk factors, to better inform the understanding of children's deaths in hospital.

- As a single-centre study, conclusions regarding contributory causes to child death are not directly applicable to the wider English National Health Service.

- Although the MDT evaluated risk factors through consensus, the study would be strengthened if the methodology had a priori agreed defined evidence-based criteria for risk factors and had adopted a more scientific approach to determining inter-rater variability.

- Only $5 \%$ of child death review meetings engaged representation from the primary healthcare team which may have impacted on a true appreciation of factors in the family and environment.

- This methodology does not allow firm conclusions to be drawn on population risk factors for death as detailed child and parent data were not gathered on all hospital admissions.

\section{INTRODUCTION}

The UK has one of the highest child mortality rates in Europe. ${ }^{1}$ Understanding the determinants of such poor outcomes requires a standardised approach to reviewing child deaths at a local, regional and national level. Although the current system, whereby the Office for National Statistics publishes annual reports on registered deaths, provides high-level epidemiological data, several limitations impede its ability to inform health strategy to reduce child mortality. These include: inaccuracies in the death certification process, ${ }^{23}$ restrictions imposed by reliance on a single cause of death and an inability to go beyond identification of 
what the patient died from to consideration of how that patient died with that condition at that time.

In England Local Safeguarding Children's Boards have a statutory responsibility for reviewing all child deaths. ${ }^{4}$ The processes to be followed are described in Working Together to Safeguard Children. ${ }^{5}$ A prospective investigation of individual 'unexpected' deaths and a retrospective review of all deaths by a regional Child Death Overview Panel (CDOP) aim to provide a comprehensive dataset to compliment national registration statistics. Although this approach has been successfully adopted for reviewing 'unexpected' deaths in the community, anecdotal experience suggests that a similarly systematic review of children's deaths in hospital does not occur. ${ }^{6}{ }^{7}$ In hospital, the standard vehicle for reviewing children's deaths is the 'Mortality and Morbidity' (M\&M) meeting. However, formats for these meetings vary widely, ${ }^{8}$ and there is little evidence of their effectiveness in improving patient outcomes. ${ }^{9} 10$

Mortality review processes in the National Health Service (NHS) are currently under close scrutiny. NHS Improvement in collaboration with the Royal College of Physicians has introduced a national mortality case review programme that aims to introduce standardised methodology for reviewing case records of adult patients who have died in acute general hospitals. In paediatrics, NHS England is developing a national paediatric mortality database to harness the intelligence arising from regional CDOPs and local child death review meetings. ${ }^{11}$ The dataset for such a database will likely include metrics relating to demographics, categorisation and preventability of death, and its success is part predicated on there being clinically informed regional child death review processes to ensure high quality data collection. Since most children die in hospital, ${ }^{12}$ these expectations provide an opportunity for processes in hospital child death (M\&M) meetings to be standardised in order for conclusions regarding issues such as contributory factors to death and preventability to have validity.

With this in mind, our hospital developed a standardised approach to reviewing hospital deaths based on the following principles:

- attendance by key professionals across the healthcare pathway;

- a framework that formally assesses contributory factors across domains intrinsic to the child, the family and environment, parenting capacity and service delivery;

- a focus on learning of lessons to prevent future child deaths.

In this paper, we present our findings from using such a framework and make recommendations for future practice.

\section{METHOD}

The Bristol Royal Hospital for Children provides tertiary paediatric services in South West England. It serves a population of approximately 933000 children (0-16years) that increases significantly during the holiday season. Since 2008, all hospital deaths have been individually reviewed using a standardised approach at a specially convened child death review (CDR) meeting. The approach broadly replicates that advocated by the UK Government for reviewing 'unexpected' child deaths in the community. ${ }^{5}$

The CDR meeting is a multiprofessional meeting that invites the key professionals involved in the child's care across allied health, social services, pathology, patient safety, primary, secondary and tertiary care. The Chair of the meeting was commonly a senior consultant in the paediatric intensive care unit. If this individual was the named consultant with responsibility for the child then the position defaulted to another senior colleague. If the death involved a joint agency response then the chair would be the Designated Community Paediatrician. In rare events where there was loss of trust between health professionals and the family, an independent chairperson from outside the organisation was sought. Videoconferencing and conference call facilitated attendance and professional unable to attend were invited to submit information using a standardised pro forma. The parents were considered central to the process and were invited to submit questions or concerns. Figure 1 illustrates a typical meeting.

Comprehensive clinical, social and epidemiological data were gathered in advance, and a template summarising contributory factors, categorisation of death and preventability was completed at the meeting's conclusion on a Form C (online supplementary appendix A). Contributory factors were assigned using a bioecological framework: factors intrinsic to the child; family and environment; parenting capacity; and service provision. ${ }^{513}$ Within each domain, a contributory factor was accorded a varying level of influence: $0=$ information not available; $1=$ no factor identified or factor identified that was unlikely to have contributed to death; $2=$ factor identified that may have contributed to vulnerability, ill-health or death; $3=$ factor identified that provided a complete and sufficient explanation for death. Deaths were classified into 10 nationally recognised categories (online supplementary appendix A). Preventability of the child's death was categorised depending on the presence of modifiable factors; namely whether the CDR had identified 'one or more factors which, in any domain, may have contributed to the death of the child and which, by means of nationally or locally achievable interventions, could be modified to reduce the risk of future child deaths ${ }^{12}$ The determination of categorisation, contributory factors and preventability was a collective decision by the multidisciplinary team (MDT). The recommendations arising from the CDR informed the wider hospital governance programme and the Form $\mathrm{C}$ forwarded to the regional CDOP. The parents were routinely invited to meet with appropriate members of their clinical team prior to and after the CDR meeting.

We conducted a service evaluation of the CDR meetings for all hospital deaths (excepting children declared dead in the emergency department) that took place between 1 April 2010 and 1 April 2013. Anonymised data were extracted from the regional CDOP database of records 
History: A 14 year old boy is knocked of his bicycle in a rural area. When the paramedics arrive the boy has a GCS of 3 . He is taken to his local hospital where the adult anaesthetist intubates and ventilates him. A CT brain scan shows a severe brain injury. The paediatric neurosurgery team request transfer directly to the tertiary children's hospital. Tragically on arrival he has fixed dilated pupils. He is transferred to the Paediatric Intensive Care unit. Brain stem death testing is performed and organ donation proceeds.

Child Death Review meeting:

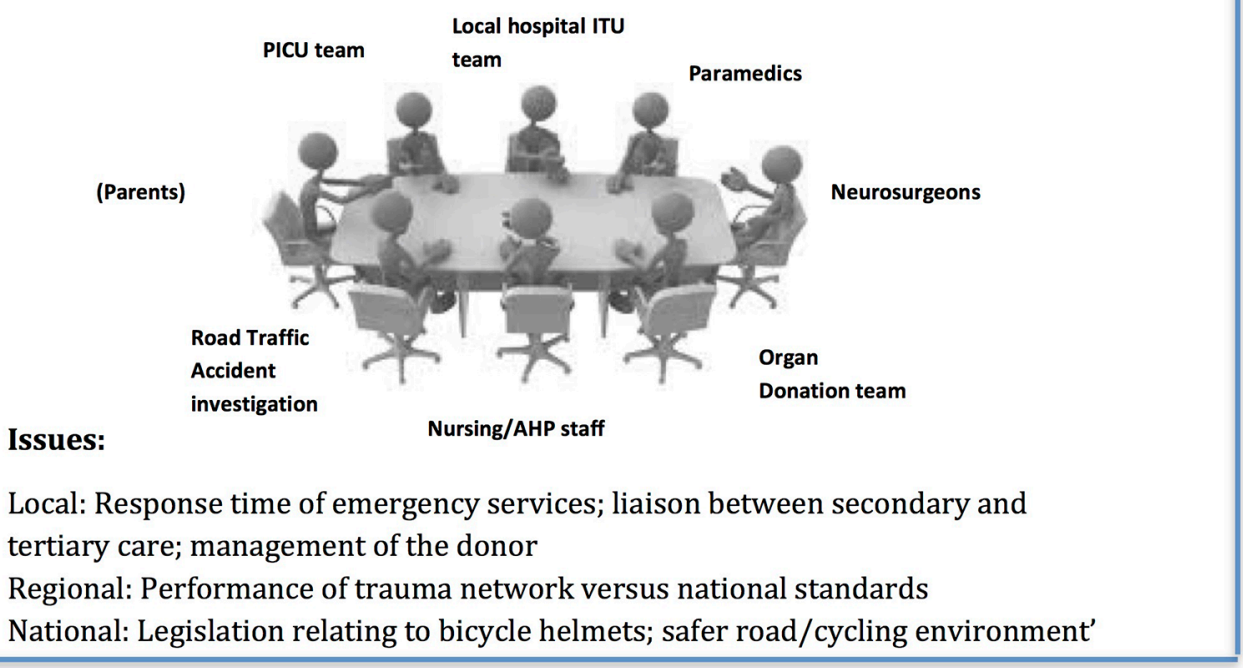

Figure 1 Schema showing attendance at a representative hospital child death review meeting. PICU, paediatric intensive care unit.

held centrally by the Child Death Enquiries office. It was not deemed necessary to obtain ethics approval for the analysis of routinely collected national data and permission for its use for publication purposes was gained from the CDOP office. Extracted data were coded and analysed (STATA V.12.0) to look at: demographic information; cause of death classification; and contributory factors. We stated a priori that we would perform subgroup analysis on factors related to service provision as this had been highlighted as an area of interest. Outputs were designed to show descriptive mortality data, and risk factors for death and ORs for specific exposures. Mantel-Haenszel, $\chi^{2}$ and logistic regression analyses were performed to identify risk factors for preventable deaths.

\section{RESULTS}

\section{CDR meeting data}

During the period studied there were 95 deaths. All deaths were reviewed using the standardised framework described above. Videoconference or teleconference facilities was used in $24 \%$ of meetings. The average time between death and CDR meeting was $4.5 \pm 2.4$ months. Professional representation at CDR meetings is shown in table 1.

Six families submitted questions directly to the CDR meeting and 32 families met with clinicians after the CDR meeting to receive feedback. Another three families requested a written summary of the CDR meeting outcome. The CDR multiprofessional meeting format directly facilitated the establishment of a definitive diagnosis (mainly metabolic or genetic) in $9 \%$ patients.

\section{Patient/parent demographic data}

Twenty-two per cent of deaths occurred in children within the hospital's cardiac surgical programme. Twenty-nine per cent of deaths occurred in children born prematurely. The demographic data for children and parents are shown in table 2. Fifty-five per cent of deaths were male and $45 \%$ were female; $89 \%$ of deaths occurred in children aged $0-4$ years, and $61 \%$ of these were in infants $<1$ year of age; $89.5 \%$ of deaths occurred in white children; $63 \%$ of children who died had a pre-existing chronic illness; $45 \%$ of deaths occurred between $8 \mathrm{pm}$ and 8 am, and $31 \%$ of deaths occurred on Saturday or Sunday. Parental smoking and mental health issues were commonly identified.

Categorisation of death by age grouping is shown in table 3. Most deaths were due to chromosomal, genetic and congenital anomalies (51\%), followed by infections $(11 \%)$, malignancy $(11 \%)$ and acute medical and surgical conditions $(10 \%)$. In infants, $62 \%$ of deaths were due to chromosomal, genetic or congenital anomalies, followed by infections $(9 \%)$ and malignancy $(9 \%)$. The $\chi^{2}$ test of independence between age and category of death showed weak $(\mathrm{P}=0.07)$ evidence of association suggesting that the category of death did vary by age as clinical experience would support. 
Table 1 CDR meeting data

\begin{tabular}{|c|c|}
\hline Professional group & $\begin{array}{l}\% \\
\text { Meetings } \\
\text { attended }\end{array}$ \\
\hline $\begin{array}{l}\text { BRHC PICU consultants and specialist } \\
\text { paediatricians }\end{array}$ & 100 \\
\hline Nursing representation & 63 \\
\hline $\begin{array}{l}\text { District general hospital paediatricians and } \\
\text { community paediatricians }\end{array}$ & 37 \\
\hline $\begin{array}{l}\text { Palliative care (hospice and palliative care } \\
\text { liaison nurse) }\end{array}$ & 25 \\
\hline Pathologist & 15 \\
\hline $\begin{array}{l}\text { Allied health professionals (pharmacy, } \\
\text { physiotherapy, clinical psychology and } \\
\text { biochemistry) }\end{array}$ & 9 \\
\hline $\begin{array}{l}\text { Patient safety (presenting root cause analysis } \\
\text { report findings) }\end{array}$ & 8 \\
\hline $\begin{array}{l}\text { Primary care (GP, health visitor, midwife and } \\
\text { social worker) }\end{array}$ & 5 \\
\hline Police and ambulance staff & 5 \\
\hline Public health & 1 \\
\hline $\begin{array}{l}\text { Expert (Bristol museum to assist identification } \\
\text { spider bite) }\end{array}$ & 1 \\
\hline
\end{tabular}

BRHC, Bristol Royal Hospital for Children; GP, general practitioner; $\mathrm{PICU}$, paediatric intensive care unit.

In $85 \%$ of cases, factors intrinsic to the child provided a complete explanation for death. In $11 \%$ of cases, factors in the family and environment and, in $5 \%$ of cases, factors in parenting capacity, may have contributed to the vulnerability, ill health or death of the child. In $33 \%$ of cases, factors in service provision were identified that may have contributed to vulnerability, ill health or death, and in two patients such factors provided a complete explanation for death (figure 2).

\section{Preventability}

Twenty-six per cent of deaths were classified as potentially 'preventable' according to a predefined national definition of having contributory factors in any domain that, by means of nationally or locally achievable interventions, could be modified to reduce the risk of future child deaths. Among these deaths, $86 \%$ were in children aged 0-4 years, $28 \%$ in children with genetic/chromosomal conditions and $20 \%$ in children with acute medical/ surgical conditions (table 4).

In deaths classified as 'preventable', factors in service provision were more commonly identified than factors across the other domains (table 5). Analysis suggests service provision issues related to treatment decisions (28\%), misapplication of knowledge (28\%) and teamwork (24\%) were important considerations in the management of these patients.

We attempted to use stepwise multiple logistic regression to assess the association of 'preventable deaths' with the child's other demographic features (table 2).
With significant numbers of data points missing spread throughout multiple variables (detailed as ' $\mathrm{n} / \mathrm{k}$ ' in table 2 ), confidence intervals for the model were wide with no individual factor that could be significantly statistically linked to what were clinically judged preventable deaths.

\section{DISCUSSION \\ Principal findings}

All in-hospital deaths were reviewed in a standardised manner. Secondary care and palliative care professionals attended $37 \%$ and $25 \%$ of meetings, respectively. It is important to place such attendance in context. Only specialities and agencies involved in the care of the child were invited to the meeting. For example, during the study period $65 \%$ of deaths involved children referred from hospitals in the region and in such cases it was appropriate to invite the local hospital professionals who had cared for the child. Therefore engagement by secondary care professionals was achieved in $>50 \%$ of meetings that required their attendance. Sixty-one per cent deaths occurred in infants and $29 \%$ in children born prematurely; $63 \%$ of deaths occurred in children with chronic illness; $24 \%$ in those with disability; and $62 \%$ of deaths occurred in infants with chromosomal, genetic or congenital anomalies, all factors known to contribute to child mortality. ${ }^{14-19}$ In $85 \%$ of cases factors intrinsic to the child, namely the underlying disease or injury process, provided a complete explanation for death. The CDR multiprofessional meeting format directly established a definitive diagnosis in $9 \%$ patients. In $11 \%$ of cases, factors in the family and environment and, in $5 \%$ of cases, factors in parenting capacity, may have contributed to the vulnerability, ill health or death of the child. In $33 \%$ of cases, factors in service provision were identified that may have contributed to vulnerability, ill health or death, and in two patients such factors provided a complete explanation for death. The $26 \%$ of deaths were thought 'preventable' (through identifying a contributory factor that could be modified to reduce the risk of a future child's death in the future) in keeping with other data and studies on child mortality. ${ }^{1220}$ In deaths deemed 'preventable', factors in service provision were more commonly identified than factors across other domains (OR: 4.89; $95 \%$ CI 1.26 to 18.9 ). Service delivery issues often related to problems with treatment decisions, misapplication of knowledge and teamwork.

\section{Strengths of study}

We describe the first report of using the CDR process to review children's hospital deaths. We have shown that it is possible to (a) engage key professionals involved in the management of the child across the pathway of care, (b) collect data of the sort that might be uploaded to a National Child Death Review database and (c) use a bioecological approach in discerning contributory factors and preventability. 


\begin{tabular}{|c|c|c|c|c|c|c|}
\hline Metric & \multicolumn{2}{|l|}{ Number (\%) } & Metric & Number (\%) & Metric & Number (\%) \\
\hline \multicolumn{3}{|l|}{ Sex } & \multicolumn{2}{|c|}{ Day of death } & \multicolumn{2}{|c|}{ Maternal smoking (n/k 11) } \\
\hline Male & \multicolumn{2}{|l|}{$52(54.7)$} & Weekday & $66(69.5)$ & No & $66(78.6)$ \\
\hline Female & \multicolumn{2}{|l|}{$43(45.3)$} & Weekend & $29(30.5)$ & Yes & $18(21.4)$ \\
\hline \multicolumn{2}{|l|}{ Age band } & Median age (month) & \multicolumn{2}{|c|}{ Time of death $(n / k 4)$} & \multicolumn{2}{|c|}{ Parental mental health problem } \\
\hline$<1$ & $58(61.1)$ & 1 & $8 \mathrm{am}-8 \mathrm{pm}$ & $50(55)$ & No & 77 (81.1) \\
\hline $1-4$ & $26(27.4)$ & 22.5 & $8 \mathrm{pm}-8 \mathrm{am}$ & $41(49)$ & Yes & $18(18.9)$ \\
\hline $5-9$ & $3(3.1)$ & 88 & \multicolumn{2}{|c|}{ Chronic illness } & \multicolumn{2}{|c|}{ Parental substance abuse (n/k 10) } \\
\hline $10-14$ & $6(6.3)$ & 150.5 & No & $35(36.2)$ & No & $77(91)$ \\
\hline $15-19$ & $2(2.1)$ & 233.5 & Yes & $60(63.2)$ & Yes & $8(9)$ \\
\hline \multicolumn{3}{|l|}{ Ethnicity } & \multicolumn{2}{|l|}{ Disability } & \multicolumn{2}{|c|}{ Parental ETOH abuse (n/k 10) } \\
\hline White & \multicolumn{2}{|l|}{85 (89.5) } & No & $72(75.8)$ & No & $78(91.8)$ \\
\hline Asian & \multicolumn{2}{|l|}{$4(4.2)$} & Yes & $23(24.2)$ & Yes & $7(8.2)$ \\
\hline Black & \multicolumn{2}{|l|}{$2(2.1)$} & \multicolumn{2}{|c|}{ Learning disability } & \multicolumn{2}{|c|}{ Mother unemployed (n/k 25) } \\
\hline Mixed & \multicolumn{2}{|l|}{$4(4.2)$} & No & 80 (84.2) & No & $57(81.4)$ \\
\hline \multicolumn{3}{|c|}{ Month of death } & Yes & $15(15.8)$ & Yes & $13(18.6)$ \\
\hline $\begin{array}{l}\text { January- } \\
\text { March }\end{array}$ & \multicolumn{2}{|l|}{$30(31.6)$} & \multicolumn{2}{|c|}{ Motor impairment } & \multicolumn{2}{|c|}{ Father unemployed (n/k 39) } \\
\hline April-June & \multicolumn{2}{|l|}{$19(20)$} & No & $84(88.4)$ & No & $34(60.7)$ \\
\hline $\begin{array}{l}\text { July- } \\
\text { September }\end{array}$ & \multicolumn{2}{|l|}{$24(25.3)$} & Yes & $11(11.6)$ & Yes & $22(39.3)$ \\
\hline \multirow{3}{*}{$\begin{array}{l}\text { October- } \\
\text { December }\end{array}$} & \multirow{3}{*}{\multicolumn{2}{|c|}{$22(23.1)$}} & \multicolumn{2}{|c|}{ Sensory impairment } & \multicolumn{2}{|c|}{ Single mother $(n / k 3)$} \\
\hline & & & No & $91(95.8)$ & No & $72(78.3)$ \\
\hline & & & Yes & $4(4.2)$ & Yes & $20(21.7)$ \\
\hline
\end{tabular}

ETOH, alcohol; n/k, not known.

\section{Weaknesses of study}

We recognise that, as a single centre study, its conclusions are not immediately generalisable to the wider NHS. While findings related to social demographics are of interest, firm conclusions on population risk factors for death require similar detailed child and parent data to be gathered on

Table 3 Categorisation of death by age group

\begin{tabular}{|c|c|c|c|c|c|c|}
\hline \multirow[b]{2}{*}{ Category of death } & \multirow[b]{2}{*}{$<1$} & \multirow[b]{2}{*}{$1-4$} & \multicolumn{2}{|c|}{$\begin{array}{l}\text { Age in years } \\
\text { No (\% of total cause) by } \\
\text { age }\end{array}$} & \multirow[b]{2}{*}{$15-19$} & \multirow[b]{2}{*}{ Total $(\%)$} \\
\hline & & & $5-9$ & $10-14$ & & \\
\hline Inflicted injury/abuse/neglect & $2(3.5)$ & 0 & 0 & $1(16.7)$ & 0 & $3(3.1)$ \\
\hline Suicide/deliberate self-inflicted harm & 0 & 0 & 0 & 0 & 0 & 0 \\
\hline Trauma & $1(1.7)$ & $4(15.4)$ & 0 & 0 & 0 & $5(5.3)$ \\
\hline Malignancy & $5(8.6)$ & $3(11.5)$ & 0 & $1(16.7)$ & $1(50.0)$ & $10(10.5)$ \\
\hline Acute medical/surgical condition & $4(6.9)$ & 0 & $2(66.7)$ & $2(33.3)$ & $1(50.0)$ & $9(9.5)$ \\
\hline Chronic medical condition & $3(5.2)$ & $4(15.4)$ & 0 & 0 & 0 & $7(7.4)$ \\
\hline $\begin{array}{l}\text { Chromosomal/genetic/congenital } \\
\text { anomalies }\end{array}$ & $36(62.1)$ & $9(34.6)$ & $1(33.3)$ & $2(33.3)$ & 0 & $48(50.5)$ \\
\hline Perinatal/neonatal event & $1(1.7)$ & $1(3.9)$ & 0 & 0 & 0 & $2(2.1)$ \\
\hline Infection & $5(8.6)$ & $5(19.2)$ & 0 & 0 & 0 & 10 (10.5) \\
\hline Sudden unexpected & $1(1.7)$ & 0 & 0 & 0 & 0 & $1(1.3)$ \\
\hline Total & 58 & 26 & 3 & 6 & 2 & 95 \\
\hline
\end{tabular}




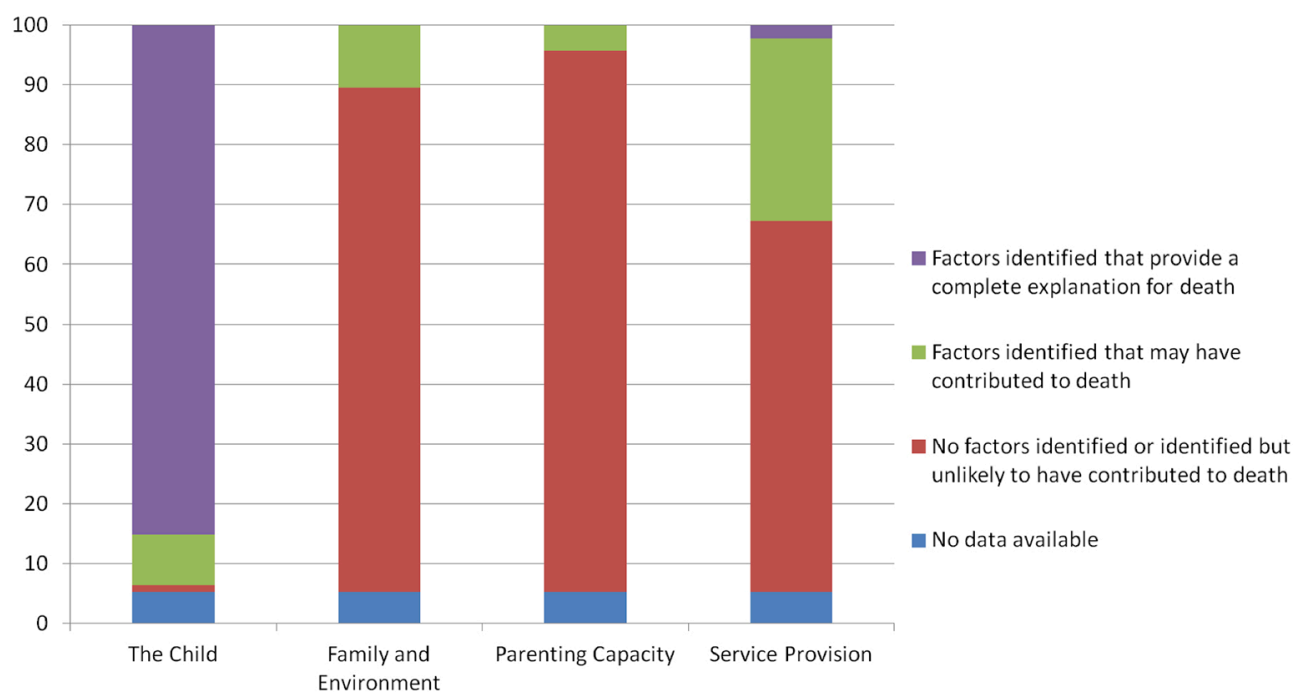

Figure 2 Contributory factors to child death by domain (100\% stacked columns).

all hospital admissions. Our study pragmatically describes a clinical dataset and, with data elements missing, was not powered for causal hypothesis testing. It was disappointing not to have more parents directly submit questions to the CDR meeting. This reflected a lack of a single point of contact with bereaved families that we have since addressed through appointing a bereavement key worker that now results in nearly $50 \%$ of meetings receiving inquiries from families. These generally fall into the following categories: cause of death, risk of recurrence in future pregnancies, why certain treatment decisions were made and whether their child's conditions/cause of death could have been prevented. Additionally, it proved very difficult to engage with general practitioners (GP) and it is acknowledged that this may have impacted on available data relating to parenting and social circumstances. In recent years, we have had more success engaging with GP through asking that they submit a very short report to the meeting outlining any

Table 4 Modifiable factors analysis by category

\begin{tabular}{lll}
\hline Category & $\begin{array}{l}\text { Number of } \\
\text { deaths (\%) }\end{array}$ & $\begin{array}{l}\text { Number of } \\
\text { 'preventable' } \\
\text { deaths (\%) }\end{array}$ \\
\hline $\begin{array}{l}\text { Total number } \\
\text { Inflicted injury/abuse/neglect }\end{array}$ & $95(100)$ & $25(26.3)$ \\
$\begin{array}{l}\text { Suicide/deliberate self-inflicted } \\
\text { harm }\end{array}$ & 0 & $2(8.0)$ \\
\hline $\begin{array}{l}\text { Trauma } \\
\text { Malignancy }\end{array}$ & $5(5.3)$ & $3(12.0)$ \\
\hline $\begin{array}{l}\text { Acute medical/surgical condition } \\
\text { Chronic medical condition }\end{array}$ & $9(9.5)$ & $5(20.0)$ \\
$\begin{array}{l}\text { Chromosomal/genetic/congenital } \\
\text { anomalies }\end{array}$ & $7(7.4)$ & $2(8.0)$ \\
\hline $\begin{array}{l}\text { Perinatal/neonatal event } \\
\text { Infection }\end{array}$ & $2(2.1)$ & $7(28.0)$ \\
\hline \begin{tabular}{l} 
Sudden unexpected \\
\hline
\end{tabular} & $10(10.5)$ & $3(12.0)$ \\
\hline
\end{tabular}

clinical involvement they may have had with the patient. The average time ( 4 months) to arrange CDR meetings was too long and related either to protracted root cause analysis (RCA) investigations or postmortem processes that were vital in informing conclusions relating to cause of death. We have now set a standard of 3 months that is adhered to in cases not involving a postmortem; it is hoped that forthcoming statutory guidance relating to CDR will concentrate efforts to address the national shortage of trained paediatric pathologists. Lastly, although the MDT made a professionally informed evaluation of contributory factors and preventability of death, the study would be strengthened if the methodology had a priori agreed defined evidencebased criteria for risk factors and had adopted a more scientific approach to determining inter-rater variability.

\section{Implications for policy}

In the context of national practice, the CDR meeting described in this paper is our term used to describe that professional meeting at which the professionals who have cared for the deceased discuss his/her care. In contrast, the CDOP involves senior leaders across health (usually community), social care, police and other agencies that have no direct involvement in the case presented before them. A concern about CDOP review is that panels are not able to make conclusions regarding contributory factors in complex 'medical' patients. The proposed model is an attempt to 'join up' these processes so that better quality data are collected for the purposes of national datasets and policy decisions. We are not proposing that all hospital 'M\&M' meetings should follow a single format. Many examples of good practice exist. However, we suggest that there may be value in hospital meetings inviting professionals across the pathway of care. It makes no sense for each service to hold its own mortality meeting; an approach that detracts from a full understanding of the issues and confuses a coordinated response to any learning that should arise. In the future, we believe further investment in teleconferencing 
Table 5 Modifiable factors analysis by domain

\begin{tabular}{|c|c|c|c|c|}
\hline Variable & Total number (\%) & $\begin{array}{l}\text { Number associated with } \\
\text { modifiable factors }(\%)\end{array}$ & $\begin{array}{l}\text { Crude OR } \\
(95 \% \mathrm{Cl})\end{array}$ & $P$ value \\
\hline Overall & $95(100)$ & 25 (26.3) & & \\
\hline \multicolumn{5}{|c|}{ Factors intrinsic to the child? } \\
\hline No & $16(16.8)$ & $6(24.0)$ & 1 & 0.27 \\
\hline Yes & 79 (83.2) & $19(76.0)$ & 0.53 (0.17 to 1.67$)$ & \\
\hline \multicolumn{5}{|c|}{ Family/environment factors? } \\
\hline No & $61(64.2)$ & $15(60.0)$ & 1 & 0.61 \\
\hline Yes & $34(35.8)$ & $10(40.0)$ & 1.28 (0.50 to 3.29$)$ & \\
\hline \multicolumn{5}{|c|}{ Parenting capacity factors } \\
\hline No & 87 (91.6) & $21(84.0)$ & 1 & 0.11 \\
\hline Yes & $8(8.4)$ & $4(16.0)$ & 3.14 (0.7 to 14.10$)$ & \\
\hline \multicolumn{5}{|c|}{ Service provision factors? } \\
\hline No & $31(32.6)$ & $3(12.0)$ & 1 & 0.01 \\
\hline Yes & $64(67.4)$ & $22(88.0)$ & 4.89 (1.26 to 18.9$)$ & \\
\hline
\end{tabular}

and videoconferencing technology, improved co-ordination with CDOP and the administrative framework that underpins emerging operational delivery networks could improve engagement with professionals not able to attend the CDR meeting in person. We advocate that analysis of a child's death requires the clinical team move away from a simple medical model to one that recognises the complex interaction between the child and his/her social and physical environment. ${ }^{21}$ This approach is best conceptualised across four domains known to contribute to child death: factors intrinsic to the child, factors in the family and environment, factors in parenting capacity and factors in service provision. ${ }^{1322}$ We support an approach by healthcare professionals that systematically examines service delivery accepting that such scrutiny will inevitably focus on aspects of decision making. We strongly support transparency in such deliberations since it is these factors in particular which may be modified to prevent future deaths. ${ }^{23-26}$ Finally, attempts by organisations to determine whether a death is avoidable are invariably subjective and fraught with difficulty. Such conclusions often detract from the real issue of consequence, namely that every child's death is a tragedy from which learning should be derived. We believe a more pragmatic approach is to steer the clinical team's focus to scrutinising behaviour that may modify future deaths. Such an approach is likely to pay dividend since it shifts the focus to active learning cycles and quality improvement.

\section{Future research}

Future research should look at parental perceptions of the CDR meeting and how best to engage bereaved families in these processes. There is a real value in codesign of local and national CDR processes with the public in order to both bring improved transparency and informed solutions. At local and national level, CDR processes also need to show an increased ability to move from case review, to SMART (specific, measurable, achievable, relevant and time bound) recommendations, to evidence-based health policy and effective interventions.

\section{CONCLUSION}

A properly convened hospital CDR requires multidisciplinary attendance by key professionals involved in the patient's management across the healthcare pathway. The contributory factors that determine a child's death are multifactorial and inevitably involve a complex interaction between the child and his/her environment. A systematic approach to CDR in the manner described leads to a better understanding of how an individual child dies of a particular condition at a particular time. Such clarity is essential for national reporting purposes, informing healthcare strategy at a local, regional and national level, and ensuring informed closure for bereaved parents.

Acknowledgements The authors thank the professionals and bereaved parents who contributed to the reviews, and A Farr, V Sleep and J Coffee in the regional Child Death Overview Panel (CDOP) office who assisted with provision of data.

Contributors DSM and JIF conceived and designed the project. DSM acquired and analysed the data. DSM drafted the written work with considerable input from JIF and MBS who revised it critically for important intellectual content and collaborated on final approval of the published version. RDM provided additional statistical analysis and comments on the final manuscript.

Funding This research received no specific grant from any funding agency in the public, commercial or not-for-profit sectors.

Competing interests During the period of study, and at the time of original writing and submission of the manuscript there were no competing interests. JIF has a long-standing interest in the causes of child mortality and subsequently has been engaged by NHS England to advise on national child death review processes.

Patient consent Not required.

Ethics approval Anonymised data in this study is routinely collected on all deceased children as per UK statutory regulation (working together to safeguard children, 2013). Permission for the use of this data for research purposes was gained from the regional child death overview panel office.

Provenance and peer review Not commissioned; externally peer reviewed.

Data sharing statement All original data from the study is available to be shared. $\mathrm{DM}$, as the primary investigator, holds all original data. 
Open Access This is an Open Access article distributed in accordance with the Creative Commons Attribution Non Commercial (CC BY-NC 4.0) license, which permits others to distribute, remix, adapt, build upon this work non-commercially, and license their derivative works on different terms, provided the original work is properly cited and the use is non-commercial. See: http://creativecommons.org/ licenses/by-nc/4.0/

(c) Article author(s) (or their employer(s) unless otherwise stated in the text of the article) 2018. All rights reserved. No commercial use is permitted unless otherwise expressly granted.

\section{REFERENCES}

1. Viner RM, Hargreaves DS, Coffey C, et al. Deaths in young people aged 0-24 years in the UK compared with the EU15+ countries, 1970-2008: analysis of the WHO Mortality Database. Lancet 2014;384:880-92.

2. Pearson GA, Ward-Platt M, Kelly D. How children die: classifying child deaths. Arch Dis Child 2011;96:922-6.

3. Hunt R, Barr P. Errors in the certification of neonatal death. J Paediatr Child Health 2000;36:498-501.

4. HM Government. Childrens Act. London: The Stationary Office, 2004.

5. HM Government. Department for Education: Working Together to Safeguard Children. London: The Stationary Office, 2013.

6. Allen L, Lenton S, Fraser J, et al. Improving the practice of child death overview panels: a paediatric perspective. Arch Dis Child 2014;99:193-6.

7. Ward Platt M. Child death review five years on. Arch Dis Child 2014;99:187-8.

8. Cifra CL, Bembea MM, Fackler JC, et al. The morbidity and mortality conference in PICUs in the United States: a national survey. Crit Care Med 2014;42:2252-7.

9. Fassier T, Favre H, Piriou V. [How to assess the impact of morbimortality conferences on healthcare quality and safety in ICU ?]. Ann Fr Anesth Reanim 2012;31:609-16.

10. Fraser J. The morbidity and mortality meeting: time for a different approach? Arch Dis Child 2016;101:4-8.

11. HC Deb 24 th June 2015,volume 597, column 88
12. Pearson GE. Why Children Die: a pilot study 2006: England, Wales and Northern Ireland. London: Confidential Enquiry into Maternal and Child Health, 2008.

13. Sidebotham P, Fraser J, Covington T, et al. Understanding why children die in high-income countries. Lancet 2014;384:915-27.

14. Saigal S, Doyle LW. An overview of mortality and sequelae of preterm birth from infancy to adulthood. Lancet 2008; 371: 261-69Singer M. Syndemics and the biosocial context of health. Lancet 2017;389:941-50.

15. Rogowski JA, Staiger DO, Horbar JD. Variations in the quality of care for very-low-birthweight infants: implications for policy. Health Aff 2004;23:88-97.

16. Heslop P, Blair P, Fleming P, et al; Confidential Inquiry into premature deaths of people with learning disabilities (CIPOLD) final report. Bristol: Norah Fry Research Centre, 2013.

17. Fraser LK, Miller M, Hain R, et al. Rising national prevalence of lifelimiting conditions in children in England. Pediatrics 2012;129:e92 3-e929.

18. Parslow RC, Tasker RC, Draper ES, et al. Epidemiology of critically ill children in England and Wales: incidence, mortality, deprivation and ethnicity. Arch Dis Child 2009;94:210-5.

19. Sldebotham P, Fraser J, Fleming P, et al. Child deaths in high income countries 2. Lancet 2014;384:904-14.

20. Department for Education. Child death reviews: year ending 31 March 2012. Department for Education: London, 2011.

21. Singer M, Bulled N, Ostrach B, et al. Syndemics and the biosocial conception of health. Lancet 2017;389:941-50.

22. Bronfenbrenner U, Evans GW. Developmental science in the $21 \mathrm{st}$ century: emerging questions, theoretical models, research designs and empirical findings. Soc Dev 2000;9:115-25.

23. Pearson GA, Ward-Platt $M$, Harnden $A$, et al. Why children die: avoidable factors associated with child deaths. Arch Dis Child 2011;96:927-31.

24. Harnden A, Mayon-White R, Mant D, et al. Child deaths: confidential enquiry into the role and quality of UK primary care. Br J Gen Pract 2009;59:819-24.

25. Wolfe I, Cass H, Thompson MJ, et al. Improving child health services in the UK: insights from Europe and their implications for the NHS reforms. BMJ 2011;342:d1277.

26. Francis R. Report of the Mid Staffordshire NHS Foundation Trust public inquiry. Mid Staffordshire: NHS Foundation Trust Public Inquiry, 2013. 